\title{
"Sou fã da revistinha": as mensagens enviadas pelas crianças ao jornalismo infantojuvenil ${ }^{1}$
}

\section{"I'm a fan of this mag": messages sent by children to the journalism made for them}

Juliana Doretto ${ }^{2}$ Encontro Anual da Compós, Faculdade Cásper Líbero, São Paulo - SP, 06 a 09 de junho de 2017. 


\section{Resumo}

Este trabalho é parte de tese de doutorado que aborda a participação de crianças na construção da narrativajornalística em veículos a eles destinados. Parte-se do pressuposto de que, ainda que o surgimento de novos meios de produção e canais de distribuição possibilite a democratização midiática, apenas a provisão de recursos não garante que os meninos e as meninas de fato influenciem na produção jornalística (BUCKINGHAM, 2009). Nesse sentido, o trabalho analisou as correspondências recebidas pela revista Ciência Hoje das Crianças, de julho de 2013 a junho de 2014. Notou-se que as missivistas, de modo voluntário ou estimulado por professores, enxergam o espaço de correspondência como uma plataforma pela qual podem intervir na oferta editorial da publicação, mas de modo reforçador, ou seja, pedindo mais do que já apreciam.

Palavras-chave

Participação, crianças, jornalismo infantojuvenil.

\section{Abstract}

This work is part of a doctoral thesis that addresses the participation of children in the construction of the journalistic narrative in vehicles intended for them. It is assumed that, although the emergence of new means of production and distribution channels allows media democratization, only the provision of resources and instruments does not guarantee that boys and girls do influence the journalistic production (BUCKINGHAM, 2009). In this sense, the paper analyzed the correspondence received by the magazine Ciência Hoje das Crianças, from July 2013 to June 2014. It was noticed that the children, either voluntarily or stimulated by teachers, see the space of letters as a platform through which they can intervene in the editorial offer of the publication, but in a reinforcing way, that is, asking for more than they already see and appreciate.

\section{Keywords}

Participation, children, children's journalism. 
"Muitas crianças têm agora acesso à tecnologia necessária para criar os seus próprios vídeos ou imagens, para imprimir publicações e para as publicar e distribuir a uma audiência muito mais vasta". Nesta frase, Buckingham (2009, p. 22) diz acreditar que o surgimento de novos meios de produção e canais de distribuição pode possibilitar a democratização midiática, no sentido de estimular a participação de crianças e jovens na produção cultural. Ao mesmo tempo, o investigador britânico relativiza a potência dessa mudança ao afirmar que, além de haver um "fosso digital" entre as crianças (as que têm ou não acesso a essas tecnologias), apenas a provisão de recursos e instrumentos não garante que os meninos e as meninas consigam de fato atuar nesse cenário midiático. Segundo ele, um processo educativo voltado para isso é primordial para que as crianças consigam usufruir dessas possibilidades.

Gallagher (2008) avança na crítica ao possível aumento da participação das crianças nas relações travadas na internet. Segundo seu estudo, há duas correntes que avaliam, de maneira oposta, o aumento da participação (das falas) das crianças no jogo social: a otimista, que acredita que esse crescimento seria "uma maneira de transformar injustas estruturas de decisão para que a voz de cada criança possa ser ouvida e seus desejos, atendidos ${ }^{3 \prime}$; e a pessimista, que entende que "a participação é muitas vezes não efetiva, com adultos consultando crianças, mas não agindo de acordo com as suas sugestões para a mudança4" (GALLAGHER, 2008, p. 404, tradução nossa).

O autor defende que esse possível aumento da participação das crianças na esfera social por conta da internet não vai mudar totalmente o cenário atual porque, retomando Foucault (1998), o poder não se manifesta de modo unilateral e homogêneo: não há uma única esfera discursiva em que os pequenos possam concentrar forças na luta por espaço para sua "vontade de verdade". Da

3 "a way to transform unjust decision-making structures so that every child's voice can be heard and their wishes acted upon." (GALLAGHER, 2008, p. 404). 
mesma maneira, não parece realista esperar que os enunciados das crianças não provocassem nenhuma mudança na rede de discursos que configura as sociedades. As transformações nas feições das infâncias contemporâneas se estabelecem, portanto, em um campo intermediário entre a mudança absoluta do estatuto de dependência e subordinação das crianças e a sua continuidade tal qual se apresentava antes das novas tecnologias de informação e comunicação.

Acrescentamos ao pensamento de Gallagher (2008) e Buckingham (2009) o fato de que, ainda que as crianças possam e sejam estimuladas a produzir seus próprios conteúdos culturais ou a refletir criticamente sobre os que são oferecidos pela mídia (e a repassar suas insatisfações aos meios produtores), é preciso ainda que uma terceira via esteja disposta a participar desse processo para que a prerrogativa das crianças se efetive. Os veículos midiáticos, principalmente os que se dedicam às crianças, precisam ouvir os meninos e as meninas, debater sobre as vozes dissonantes e implementar mudanças. É sobre esse campo que este trabalho se lança: a possibilidade que as crianças têm de se aproximarem dos veículos jornalísticos produzidos para elas, sobretudo por meio de canais digitais, faz que elas busquem participar da elaboração desse discurso jornalístico, exercitando o seu direito à representação, defendido por Buckingham (2009)?

Entendemos aqui esse direito como uma afirmação ainda não estabelecida na Convenção sobre os Direitos da Criança da Organização das Nações Unidas (ONU), de 1989, que define parâmetros gerais a serem adotados por todos os países do globo, para o tratamento das crianças e para o cuidado com elas. Esse direito iria além da prerrogativa de a criança ter acesso à informação midiática de qualidade, orientada para ela e que promova seu bem-estar social, espiritual e moral, como também sua saúde física e mental, como diz o Artigo 17 da Convenção. Lutar pelo direito à representação é, para o investigador inglês, assegurar que os meninos e meninas possam produzir suas representações da infância, além de analisar criticamente as que já circulam na mídia. Com essa premissa, este trabalho, parte de tese de doutoramento ${ }^{5}$, defende 
que, ao buscar influenciar os veículos jornalísticos produzidos para o público infantil, o que vem sendo facilitado pelas novas tecnologias de comunicação e informação, as crianças poderiam reclamar por melhores representações. Nossa investigação questiona se, em primeiro lugar, as crianças de fato aproveitam essas novas possibilidades de participação e, quando o fazem, se estão interessadas em aperfeiçoar as representações da infância no jornalismo infantojuvenil.

Nossa estratégia metodológica consistiu em recolher, categorizar e interpretar mensagens enviadas por leitores para uma revista mensal dirigida a crianças no Brasil: Ciência Hoje das Crianças ( $\mathrm{CHC}$ ). A escolha do magazine ocorreu pois, apesar de haver no Brasil outro veículo jornalístico para a infância com notoriedade no contexto nacional ${ }^{6}$, a revista Recreio, conseguimos acesso apenas às correspondências da primeira. A CHC é ligada à Sociedade Brasileira para o Progresso da Ciência (SBPC) e dedica-se à divulgação de temas científicos relacionados aos pequenos, com foco em meninos e meninas de sete a catorze anos. Com sede no Rio de Janeiro, em um dos prédios da Universidade Federal do Rio de Janeiro (UFRJ), a CHC tem um leitorado composto basicamente por crianças que recebem a revista na escola e a ela são apresentadas pela professora ou têm contato com o magazine na biblioteca do colégio. A revista chega a mais de 60 mil colégios públicos do país, sendo distribuída para bibliotecas por meio do Ministério da Educação brasileiro.

Todas essas mensagens foram analisadas segundo uma grade analítica:

- O autor do e-mail ou do comentário (se é do sexo feminino ou masculino; se é adulto ou criança);

- O e-mail do autor da missiva, quando for possível observar (se a conta é da criança ou de um adulto);

- A natureza da mensagem (crítica, sugestão, parabéns, correção etc.; subcategorias construídas a partir da leitura do material e, no caso de 
cartas com duplo teor, como parabéns e críticas, escolhemos a que predominava na carta ou a que nos pareceu mais relevante, ou seja: a sugestão de reportagem é, como categoria, de maior valor para a pesquisa do que apenas elogios à revista. Evitamos o uso de duplas categorias, sempre que possível, para tornar os resultados mais objetivos).

\section{A CHC e sua relação com o leitorado}

"Cartas" é como a revista nomeia a seção em que publica as correspondências das crianças. Com tamanho fixo de uma página e meia, o espaço traz de oito a nove cartas todos os meses. Além dos textos, o magazine também divulga desenhos que acompanham as mensagens. É nessa seção, ainda, que a revista publica a correção de erros das edições anteriores. Segundo a redação, chegam cerca de 50 cartas em papel à sede da publicação, todos os meses - número que já chegou a ser de 90 por semana. O número de e-mails e comentários no site, por outro lado, tem aumentado, segundo a editora, Bianca Encarnação7. Como há apenas três jornalistas na preparação da publicação, algumas das cartas nem são abertas, principalmente as que vêm em pacote, de uma mesma escola. Ainda assim, a subeditora, Cathia Abreu, diz que tenta responder a algumas correspondências e monitora de algum modo os conteúdos que têm sido solicitados pelas crianças: "Por exemplo, eles querem saber mais sobre piolho; têm curiosidades sobre isso". A jornalista conta também que, para editar a seção, seleciona cartas em papel (as que julga mais interessantes, com textos, relatos mais originais) e também alguns e-mails, que são gerenciados por Catarina Chagas, editora da $\mathrm{CHC}$ On-line.

As profissionais da redação contam ainda que as páginas que abordam curiosidades na revista vieram pela demanda dos leitores, que mandavam dúvidas pelas cartas. São as seções: (1) "Por que", que resolve dúvidas como "Por que temos sobrenomes?"; "Por que o tomate é fruta?" e "Por que sai fumaça 
pela boca quanto está frio?"; (2) "Você sabia que o leite das baleias se parece com leite condensado?"; "Você sabia que os peixes podem ser nossos aliados na luta contra os mosquitos?"; "Você sabia que alguns insetos cuidam dos seus filhotes?"; (3) "Como funciona a linguagem de sinais?"; "Como funciona o banheiro químico?"; "Como funciona a animação?"). "Eles não formalizavam: 'Ah, nós queremos uma seção de curiosidade'. Eles diziam: 'Queremos mais texto curto'; 'Mais texto de pergunta e resposta'. Essa [as seções] foi a nossa tradução do entendimento que vinha das cartas", diz Encarnação. Ela explicou ainda que a seção "Quando crescer, vou ser", sobre carreira, também surgiu a pedido do leitorado.

\section{Mensagens recebidas}

Foram analisadas 250 correspondências, enviadas à revista no período de julho de 2013 a junho de 2014: dessas, 195 foram correios eletrônicos e as demais, cartas em papel. Das mensagens às quais tivemos acesso, foram consideradas aquelas enviadas para o endereço eletrônico chc@cienciahoje.org.br (não foram investigados comentários enviados pelo canal de participação do site da $\mathrm{CHC}$, mas apenas as mensagens de quem se comunica diretamente com a revista no formato impresso, objeto desta pesquisa). Os e-mails das crianças chegaram à nossa posse por meio de nuvem digital, mas a outra metade da amostra pesava algo considerável: a editora separou, em uma grande caixa de plástico, cerca de duas centenas de cartas em papel, praticamente todas escritas à mão. Eram sobretudo pacotes com uma ou duas dezenas de cartas em papel, enviadas pelo correio para a revista, com mesma data de expedição e, muitas vezes, com uma mesma identificação de remetente: o nome de uma escola. No texto de cada uma das cartas, a assinatura de um aluno ou de uma dupla deles.

Das cartas em papel, analisaram-se todas as correspondências individuais, como também todas as coletivas assinadas por duas ou mais crianças, ou por um professor e seus alunos, e cerca de metade das cartas coletivas "escolares", ou seja, enviadas por vários estudantes de um mesmo colégio (em geral, do mesmo ano 
também). Essa decisão partiu da observação de que as correspondências seguiam um padrão muito claro, a saber: apresentação do leitor; um comentário sobre um ou mais textos publicados pela revista; e, em alguns casos, uma sugestão de tema de reportagem. Com a repetição do padrão, notou-se a saturação da amostra e o trabalho com um conjunto menor, porém representativo de mensagens, pareceunos ser uma estratégia que permitia a investigação mais aprofundada dos dados. Além disso, os pacotes com várias cartas enviadas por uma mesma turma foram considerados como uma única unidade; ou seja, uma carta coletiva. No entanto, atentou-se para a categorização do conteúdo de todas elas, com exceção de mensagens que traziam assuntos estranhos à revista ou textos compostos por frases soltas ou que nem faziam referência à publicação (pareciam não terem sido lidas pelo professor; o aluno pode ter enviado um texto aleatório ao magazine, apenas para cumprir a tarefa dada pelo docente).

Nos casos em que houve cartas cuja autoria era de um professor e seus alunos, acrescidas de cartas assinadas também individualmente, por esses mesmos estudantes, analisamos com mais pormenor a primeira, por ter caráter mais geral. Não será feita aqui a divisão, na maior parte da análise, entre as mensagens enviadas por correio e as eletrônicas pois, na maioria dos casos, nos interessa a totalidade dos leitores que se comunicam com a revista (por exemplo, ao analisarmos o tipo de sugestão recebida ou o gênero dos missivistas, não importa se a correspondência veio em papel ou em forma eletrônica; preocupamo-nos com o que o leitor diz). Uma hipótese para explicar esse cenário pode ser o restrito acesso à internet das crianças brasileiras, principalmente na rede escolar: 37\% dos estudantes do Brasil que têm entre nove e dezessete anos acessam a rede em suas escolas. No entanto, o envio de cartas escritas à mão também pode ser uma escolha docente, para que as crianças redijam esse tipo de missiva, que cai em certo desuso com a internet. Pode haver ainda certa resistência dos professores em usar as novas tecnologias, mesmo quando elas estão presentes, como pesquisas vêm demonstrando (BARBOSA, 2014a). De todo modo, observando as cartas 
enviadas à $\mathrm{CHC}$, percebe-se que restrições no contato com as formas digitais de conexão não acarretam menor participação, já que as correspondências em papel também funcionam como canal de comunicação entre o leitorado e o magazine (ainda que parte desse engajamento tenha sido impulsionado por professores).

\section{Quem envia as mensagens?}

As cartas coletivas dominam a autoria, com quase metade (48\%) das mensagens, e as meninas têm participação mais relevante do que os meninos: elas enviam $31 \%$ das cartas, enquanto os meninos ficam com metade desse valor, 14\%. Correspondências de professores e outros funcionários de escola, como secretários ou coordenadores, além de pais, compõem os restantes 7\% (Gráfico 1).

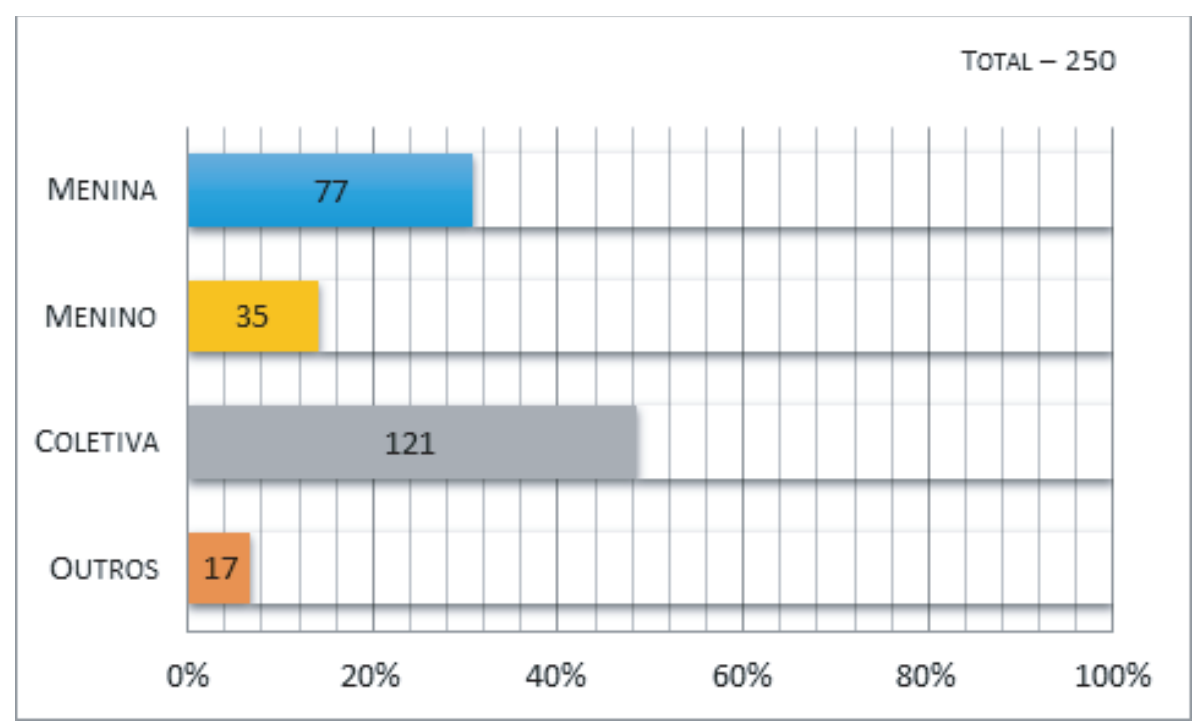

Gráfico 1: CHC - Quem envia as mensagens (número de mensagens e \%)

A explicação para esse destaque notório das correspondências coletivas assenta em dois elementos. O primeiro é a importância dos exemplares vendidos para as escolas na sustentabilidade financeira da publicação o que se reverte na presença da revista em sala de aula e em bibliotecas e na sua utilização como material didático (e o envio das cartas de leitor é uma dessas atividades acadêmicas, como já haviam antecipado as profissionais da redação). Há ainda 
um claro declínio das cartas em meses não escolares ou já próximos às férias (janeiro, fevereiro e junho) $)^{8}$.

O segundo é o estímulo específico para essa escrita de correspondência, encontrado nesta pesquisa, no material de apoio ao docente da rede pública de ensino estadual de São Paulo, no programa "Ler e Escrever", "um conjunto de linhas de ação articuladas que inclui formação, acompanhamento, elaboração e distribuição de materiais pedagógicos e outros" ${ }^{\prime \prime}$. No material do 30 ano, há uma atividade chamada "Produção de cartas do leitor", em que "o objetivo é que os alunos façam uso dos vários conhecimentos adquiridos sobre cartas e sobre a análise de matérias jornalísticas para se posicionarem a respeito de uma matéria escolhida, e redijam, com sua [do professor] ajuda, uma carta do leitor". Além disso, há nesse manual uma proposta de leitura das cartas dos leitores publicadas especificamente na CHC: "Assim se garante um contato significativo com esses textos ao inserir sua leitura num momento em que os alunos se aproximam da organização da revista e de suas diferentes seções, além do contato com os autores dessas cartas, que são outras crianças que leem a revista"10. Não há uma recomendação para que a mensagem seja escrita à mão e enviada apenas por correio tradicional ${ }^{11}$. Há vários exemplos desse uso escolar da carta de leitor, em falas de professores e alunos de São Paulo presentes nas mensagens analisadas:

Conhecemos a revista esse ano ao estudarmos o gênero carta de leitor. (Carta coletiva; $4^{\circ}$ ano e professora; novembro de 2013; Caieiras, SP).

Estou trabalhando carta de leitor com meus alunos [...] gostaria que publicassem nossa carta.

(Carta coletiva; 4a ano e professora; setembro de 2013; São Paulo, SP). 
Eu a minha turma vamos fazer a prova do Saresp ${ }^{12}$, por isso estamos estudando sobre a carta do leitor e suas revistas têm nos ajudado muito para nossa aprendizagem.

(Carta coletiva; $5^{\circ}$ ano; novembro de 2013; Américo-Brasiliense, SP).

Temos a assinatura da revista $\mathrm{CHC}$, lemos a revista em sala de aula. Gostamos muito da reportagem: Por que o cachorro abana o rabo quando está feliz? (Carta coletiva; 40 ano; novembro de 2013; Bragança Paulista, SP).

Nesse bimestre nossa apostila citou o gênero textual carta ao leitor da CHC. (Carta coletiva; $3^{\circ}$ ano; abril de 2014; Palmital, SP).

Nós estávamos trabalhando o projeto cartas de leitor e resolvemos escrever para vocês quando lemos a reportagem "Na Escola Quilombola". (Carta coletiva; $4^{\circ}$ ano; dezembro de 2013; Itatiba, SP).

Sobre a faixa etária, o número de crianças que informa a idade nas cartas é muito pequeno (apenas 64, sendo 42 meninas). Isso se dá principalmente pelo fato de as mensagens coletivas representarem quase $50 \%$ da amostra: nelas, os estudantes indicam a sua série escolar, não os anos que têm. Pela pequena amostra, não fizemos análise percentual dos dados, mas apresentamos nos Gráficos 2 e 3 os números absolutos, divididos por gênero. Realçam-se os dez e os onze anos, nos dois casos.

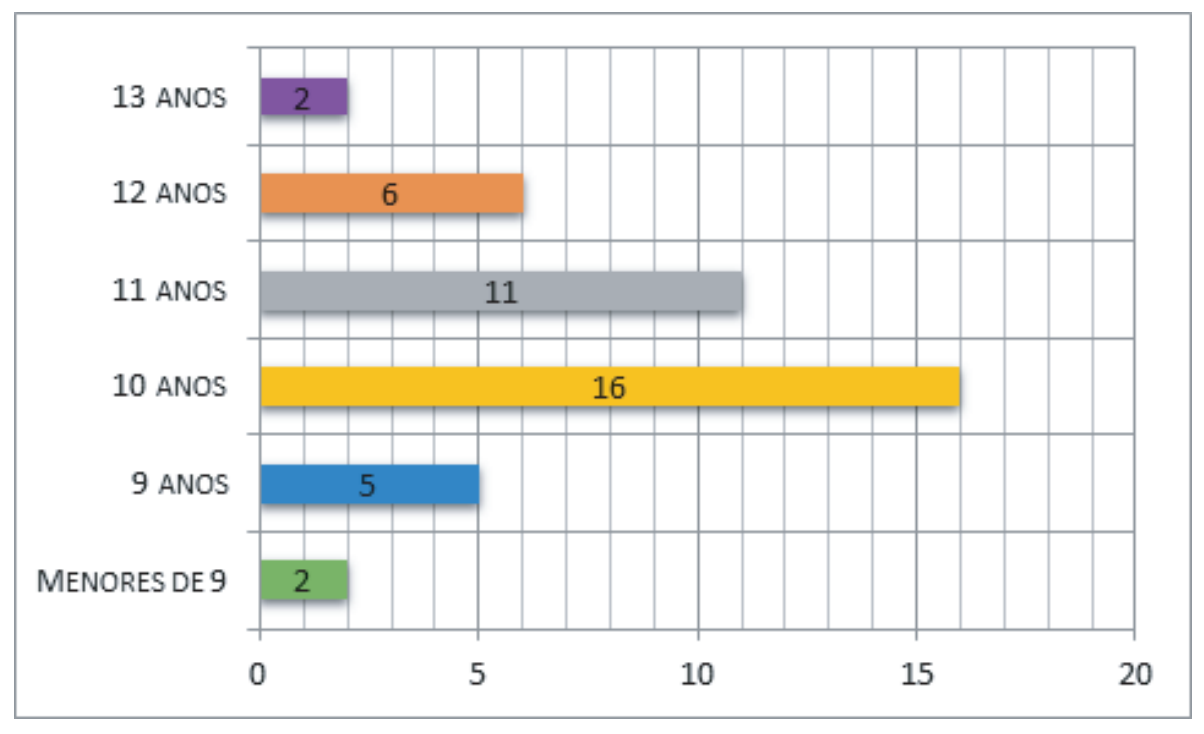

Gráfico 2: CHC - Idade das meninas que enviam mensagens (número de crianças) 


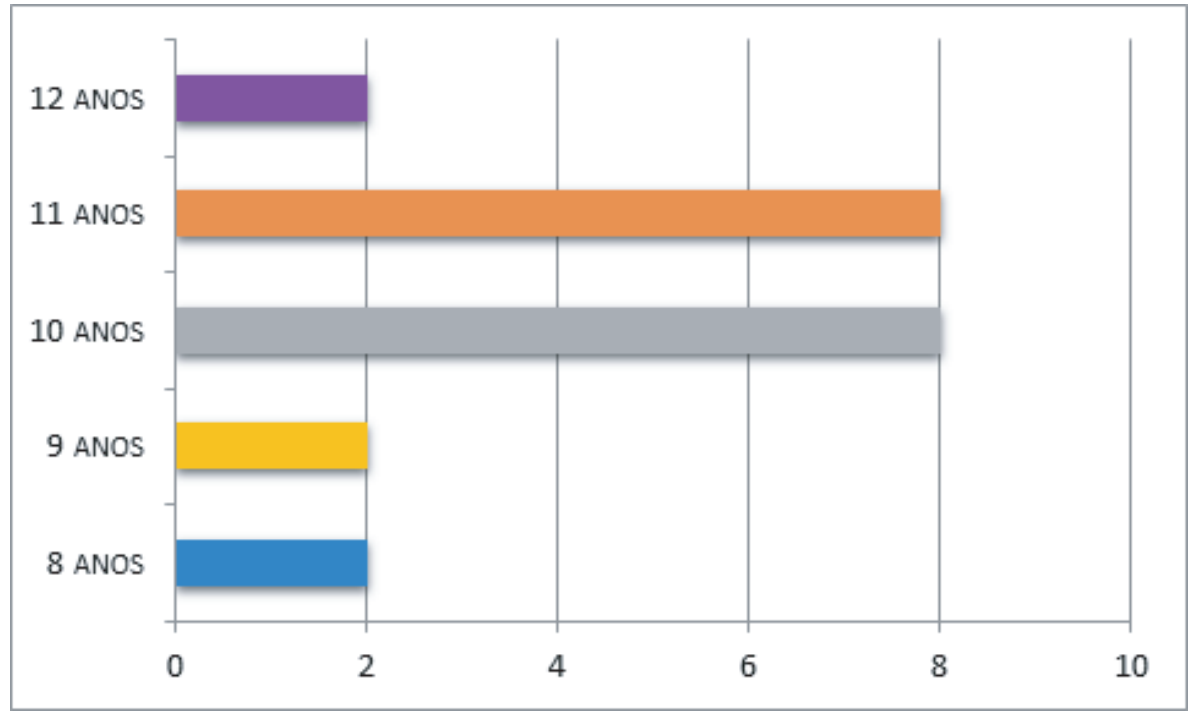

Gráfico 3: CHC - Idade dos meninos que enviam mensagens (número de crianças)

Na amostra das correspondências coletivas, das 121 cartas, 94 trouxeram a informação sobre a série escolar frequentada, sendo praticamente $50 \%$ delas do quarto ano - que, no Brasil, corresponde ao ensino de crianças de nove e dez anos de idade. Outros $30 \%$ vêm do quinto ano, que seriam crianças com dez e onze anos de idade, em média (Gráfico 4). Esse dado pode indicar apenas que o uso da $\mathrm{CHC}$ em sala de aula e o estímulo ao envio de cartas são maiores nessas séries, mas, se cruzarmos esses indicadores com as correspondências individuais que informam a idade, nota-se a correspondência de faixa etária dos dez e onze anos. Porém, mesmo nesses casos de missivas individuais, são frequentes os indicadores de que o contato com o magazine se dá na escola, o que gera uma influência indireta ${ }^{13}$ do ambiente acadêmico ou da ação docente no envio da correspondência pelas crianças: de mensagens eletrônicas foi enviado por uma mesma turma de alunos, mas, como não foi possível certificarmos de que se tratava de fato de uma correspondência feita de modo coletivo - poderia ser apenas uma coincidência, com e-mails enviados no mesmo dia por crianças de uma mesma grande cidade, por exemplo -, mantivemos a classificação da mensagem como "individual". 
É a primeira vez que escrevo esta carta. Eu gosto muito da revista $\mathrm{CHC}$ sempre leio ela [sic] na biblioteca da escola.

(Menino; agosto de 2013; Caraguatatuba, SP).

Eu conheci a CHC na biblioteca da escola. Esta revista é demais.

(Menino de 10 anos; julho de 2013; Muriaé, MG).

Parabéns pela revista mais popular das escolas.

(Menino de 10 anos; novembro de 2013; Bauru, SP).

[...] e na minha escola eu estava lendo a revista CHC vi um tema por que sentimos nojo e achei superinteressante.

(Menina de 10 anos; novembro de 2013).

Minha professora lê a revista para mim e para meus colegas de sala. (Carta coletiva; menino de 6 anos e menina de 7; novembro de 2013; Guaianazes, SP).

Gosto muito de ler a CHC [ilegível] aprendo e converso sobre diferentes assuntos, com meus amigos na escola e na minha casa.

(Carta coletiva; dois meninos de 9 anos; novembro de 2013; São Paulo, SP).

Os dados sobre a interação das crianças com ferramentas de comunicação on-line no Brasil, segundo a pesquisa TIC Kids Online Brasil, realizada pelo Comitê Gestor da Internet no Brasil (com entrevistas a 3 mil crianças), mostram que os adolescentes, a partir dos 13 anos, publicam muito mais mensagens em páginas da internet ${ }^{14}$; porém, como os jovens não fazem parte do público da $\mathrm{CHC}$, não era esperado que eles aparecessem com destaque entre o leitorado que se comunica com a revista. Os indicadores sobre essas atividades de comunicação das crianças que têm entre nove e doze anos, no entanto, apontam uma diferença muito pequena entre os gêneros. Essa divisão mais igualitária, no entanto, não está representada na amostra de cartas da $\mathrm{CHC}$, já que as meninas enviaram cerca de $50 \%$ a mais de mensagens para a revista do que os meninos - ainda que as correspondências das garotas sejam praticamente dois terços do que representam as cartas coletivas. A resposta a isso pode estar na natureza da amostra, bastante vinculada ao trabalho escolar, o que não refletiria o movimento espontâneo de comunicação que a pesquisa TIC Kids Online Brasil buscou detectar. 


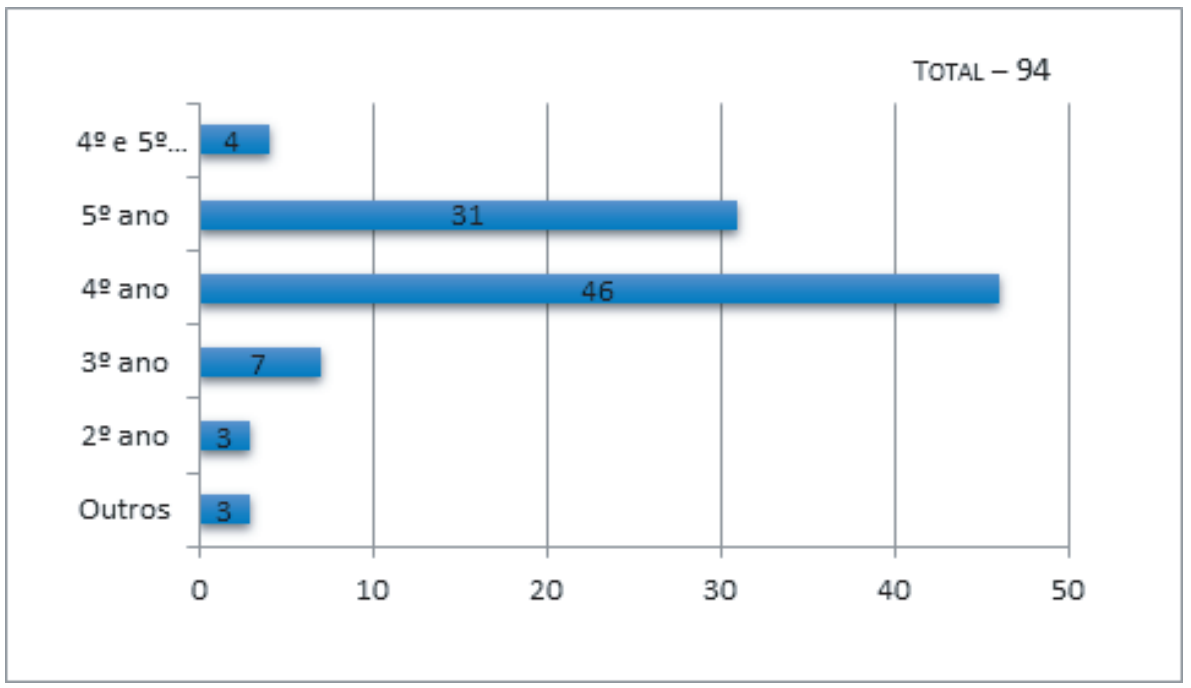

Gráfico 4: CHC - Séries escolares das mensagens coletivas (número de mensagens)

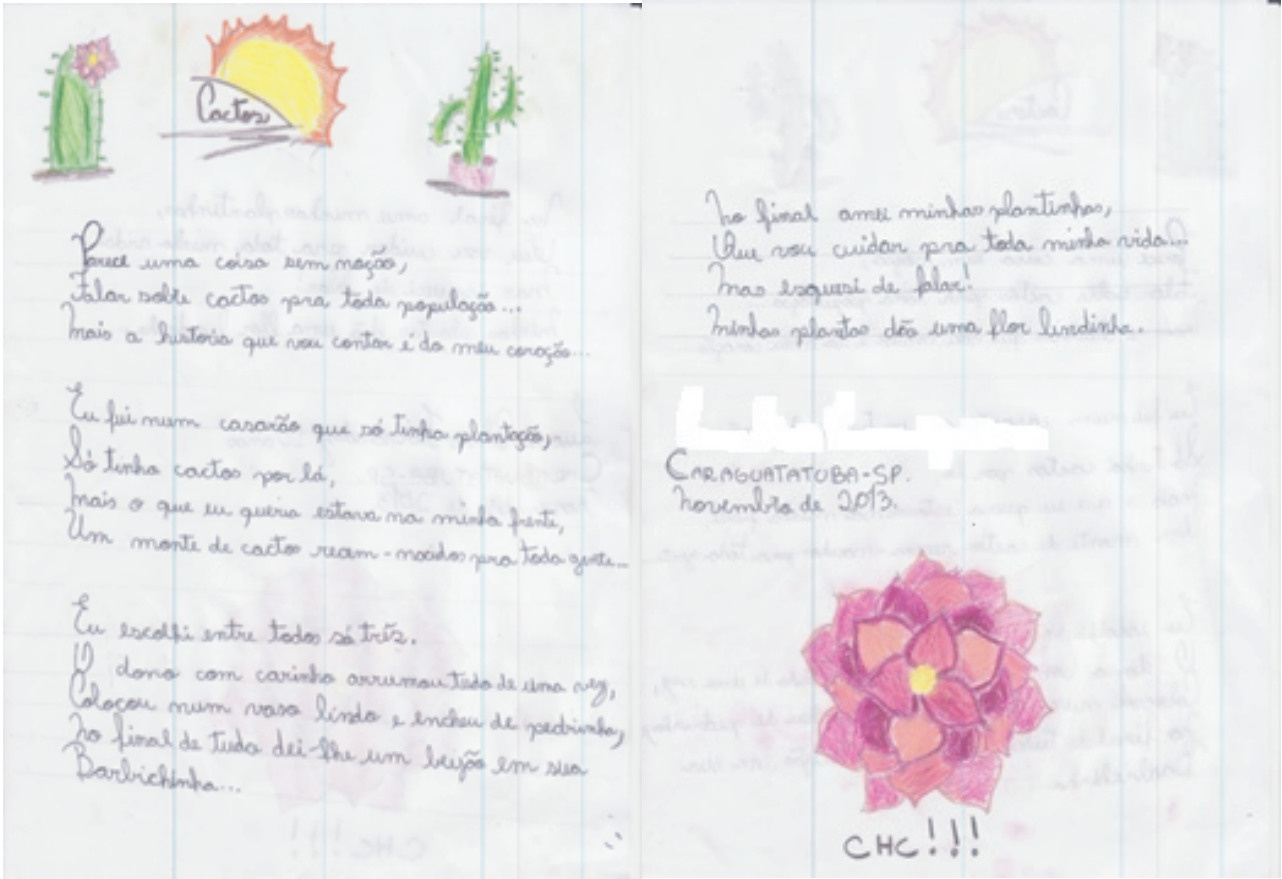

Figura 3: Exemplo de poema enviado por leitor da $\mathrm{CHC}$

Assim, ainda que as meninas tenham preponderância nas correspondências individuais, o perfil do leitorado que escreve à $\mathrm{CHC}$ não é formado por elas, mas por um leitor "aluno", garoto ou garota, e que manda mensagens à revista impulsionado (ou compelido) por docentes. Como dito, a revista brasileira, por ter temática claramente vinculada ao conteúdo escolar (a divulgação científica), é bastante utilizada como material educativo, e o exercício de escrita da "carta do 
leitor" parece vir na esteira desse uso. Em resumo, podemos afirmar que o leitor que escreve à $\mathrm{CHC}$ é do tipo escolar e flutuante: ele, menina ou menino, com dez ou onze anos, lê esporadicamente a publicação, de acordo com o emprego do magazine em sala de aula ou da exposição dele na biblioteca escolar.

\section{O que dizem as mensagens?}

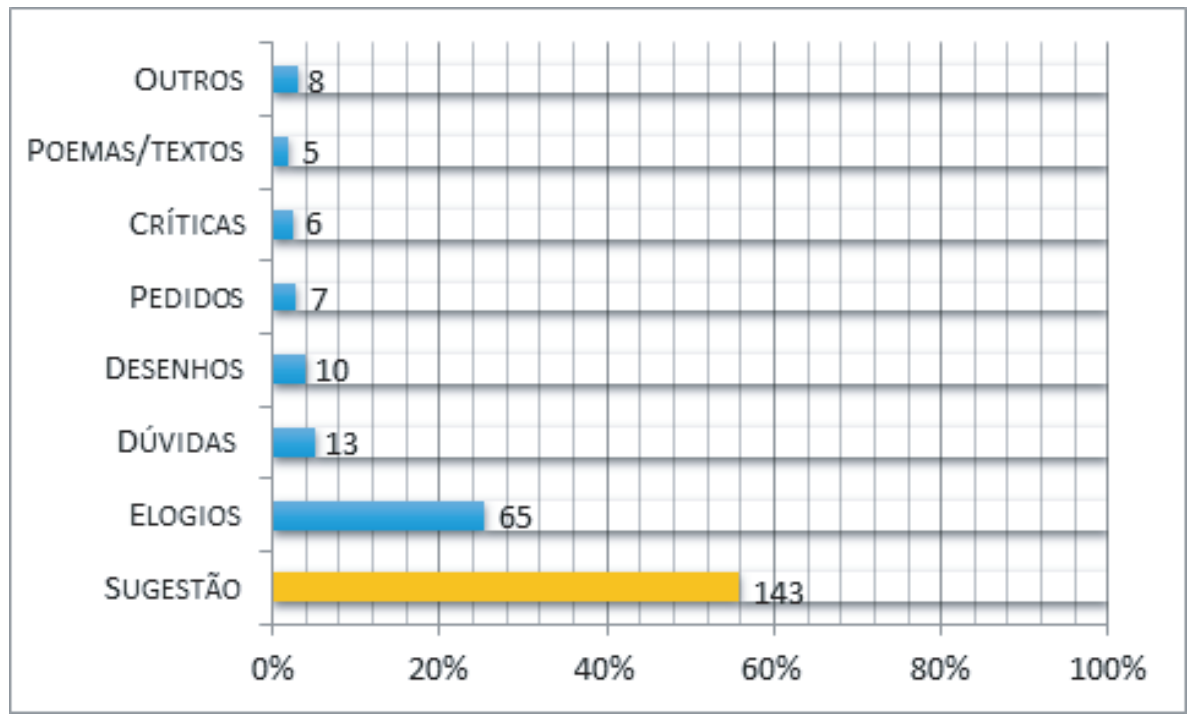

Gráfico 5: CHC - O que dizem as mensagens (número de mensagens e \%) - sete cartas foram classificadas em duas categorias simultaneamente

No Gráfico 5, vê-se que as sugestões correspondem a quase $60 \%$ das missivas enviadas, muito à frente dos elogios, com pouco mais de $20 \%$, enquanto as demais categorias apresentam valores irrisórios: são envios de desenhos, poemas ou textos literários (que os leitores pedem para que sejam publicados na revista); dúvidas relacionadas ao Clube do Rex (uma rede social criada pela revista) ou a curiosidades ("Quantos anos teria o inventor da calculadora?" ou "Existe algum animal que sorri ou dá risada?", cartas de meninas, sem idades descritas); pedidos (para sair do Clube do Rex, receber mensagens eletrônicas com novidades da revista ou ter cartas publicadas ${ }^{15}$ ); e críticas a textos ("Algumas 
palavras são difíceis de entender na reportagem 'Buracos negros'"; carta coletiva, assinada por menino e professora), categoria que também incluiu a indicação de erros ou a demora na resposta ao e-mail. A proporção se mantém nas cartas individuais: das 112 cartas enquadradas nesse indicado, mais da metade envia sugestões - 61 mensagens, 34 de meninas e 27 de meninos. Desse modo, ainda que as cartas coletivas sugiram temas para reportagem ou seções por seguirem um modelo proposto por professores ou por um material didático, os missivistas individuais colaboram com quase metade das mensagens que propõem ideias para as revistas.

Olhando para os tipos de sugestão (Tabela 1), predominam proposições sobre animais e carreira (para a seção "Quando crescer, vou ser..."). No primeiro caso, as crianças sugerem textos sobre dinossauros e outros animais extintos, além de morcegos, pássaros, cisnes, peixes, golfinhos, elegantes, cavalos-marinhos e insetos, entre outros. No segundo, surgem propostas para reportagens sobre engenheiros, nutrólogos, advogados, estilistas, polícias, biólogos, cantores etc. Em seguida, aparecem ideias relacionadas à natureza (furacões; transgênicos; poluição; extinção de vulcões; raios; energia solar; reciclagem; biodiversidade etc.); a curiosidades em geral, sobre os mais diversos temas (matéria sobre invenções fantásticas e seus inventores; por que nascem cabelos brancos; como os cadernos são feitos; como foram criadas a pasta e a escova de dentes; como funcionam o DVD e o som; reportagem sobre a numeração de calçadas; de onde veio a maquiagem etc. ); proposições para a configuração da revista (mais jogos; mais "coisas engraçadas"; mais histórias em quadrinhos; mais páginas com "assuntos interessantes"; piadas envolvendo assuntos de ciências; ou como sugerido na carta de uma menina sem a idade mencionada: "como muitos jovens hoje em dia ficam quase o dia inteiro no celular e quase nunca eles arranjam "tempo" para ler, vocês podiam fazer um app [aplicativo] da CHC)". 


\begin{tabular}{lc}
\hline Principais sugestões & N. de mensagens \\
\hline Animais & 38 \\
\hline Carreira & 33 \\
\hline Natureza & 25 \\
\hline Curiosidades & 17 \\
\hline Revista & 15 \\
\hline História & 8 \\
\hline Esporte & 7 \\
\hline Ciências & 7 \\
\hline
\end{tabular}

*Cartas em múltiplas categorias, o que inviabiliza a porcentagem

Tabela 1: CHC - O que as mensagens dizem?

O escrutínio dessas sugestões revela que, assim como apontado de maneira geral nos estudos sobre a relação das crianças com as notícias (AUTOR, 2013), os animais e a vida natural atraem bastante o interesse infantil, mas revela também que a preocupação com o futuro, expressa na escolha da profissão, é fonte de preocupação das crianças e elas anseiam por mais informações sobre o tema.

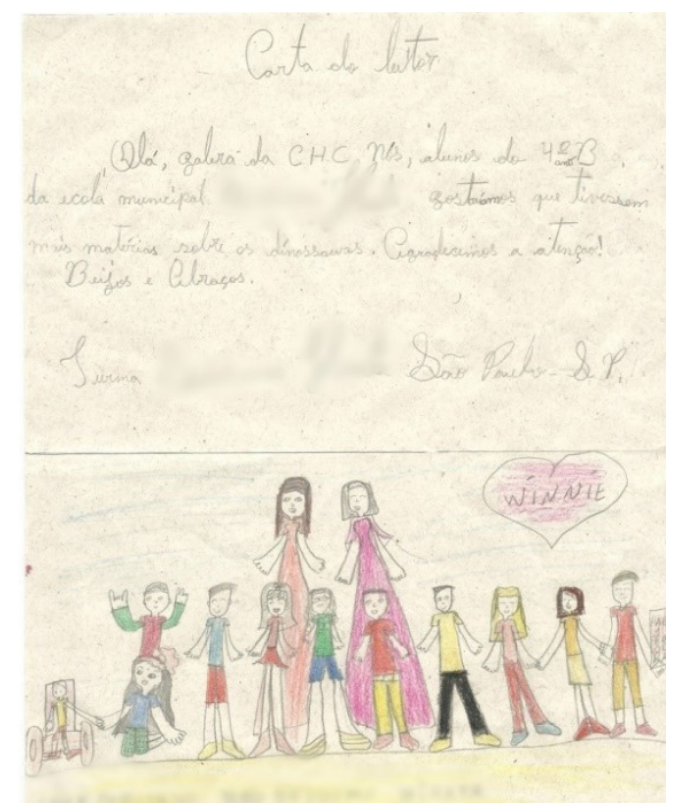

Figura 4: Exemplo de carta coletiva enviada à revista $\mathrm{CHC}$

É necessário registrar ainda algumas observações. Como a amostra tem grande proporção de cartas produzidas em ambiente escolar, nota-se 
que, como as crianças leem e comentam edições passadas da revista, e não necessariamente a mais atual - reforçando o papel de leitores flutuantes -, as sugestões por vezes pedem temas abordados recentemente no magazine. Além disso, talvez para completar a tarefa escolar dada, as crianças, com alguma recorrência, elogiam certa reportagem e, como sugestão, pedem apenas que a revista escreva mais sobre isso. Isso demonstra que os leitores gostaram do que leram e têm certo gosto pela repetição (não se importam em terem mais contato com essas temáticas), mas que também ou não têm muito conhecimento do cardápio informativo do magazine ou simplesmente não se esmeraram na feitura das cartas. Por fim, há três casos ainda em que esse desconhecimento chega ao ponto de os missivistas confundirem a revista com um livro: "Gostei muito do seu livrinho"; "Pessoal da CHC, adoro os livros de vocês e vou continuar a ler" (frase de duas meninas, enviadas numa carta coletiva de 50 ano); "Gostou de um livro cujo tema foi 'Se quer aprender, durma'"' (menina, dez anos, Barra da Estiva, BA). Isso também pode indicar que as crianças têm pouca relação com revistas em geral e não conseguem diferenciar um veículo jornalístico de uma outra obra editorial.

Destacamos também o apreço que as crianças demonstram pelos personagens criados pela revista - principalmente entre as meninas, que se referem a eles com carinho. A Turma do Rex, isto é, os dinossauros Rex e Diná e o zangão Zíper são as mascotes do magazine e aparecem em histórias de quadrinhos:

eu a conheci [a revista] por meio da escola, quando minha professora de arte e leitura pediu para fazer uma atividade. [...] Sou fã do Rex. (Menina de 11 anos; agosto de 2013).

Eu li só duas revistas, mas por enquanto estou adorando. A nossa escola tem as revistas há muito mais tempo, só agora me dei conta que é tão legal. Adorei a Dina, o Rex, Zíper e todos os personagens da CHC. (Menina; setembro de 2013; moradora de fazenda em MT).

Beijos e abraços para o Rex, a Diná e o Zíper.

(Carta coletiva; 40 e $5^{\circ}$ anos; outubro de 2013; Gardênia, SP).

Um beijo para o Rex, pois seus quadrinhos são o máximo! (Menina de 11 anos; novembro de 2013). 
Eu adorei o personagem Rex e sou fã da revistinha.

(Carta coletiva; $5^{\circ}$ ano; novembro de 2013; Monte Alto, SP).

As minhas seções favoritas da revista são as tirinhas do Rex e a das experiências.

(Menino de 11 anos; novembro de 2013; São José dos Campos, SP).

Assim, temos na $\mathrm{CHC}$, em resumo, um leitorado escolar e flutuante, de voz coletiva e induzido, ou seja, que responde a um estímulo professoral e, incentivado por isso, entende a produção do jornalismo infantojuvenil como um processo em que pode intervir, sugerindo temas para reportagens e ideias de seções ou afirmando que o veículo de comunicação segue um bom caminho. No entanto, essas crianças autoras ainda são bastante tímidas em relação a fazer críticas ou apontar erros à revista, e um garoto que pede "desculpas" ao criticar a CHC é um exemplo paradigmático disso: "Só não gostei muito do artigo "A mocinha e os sapos", da CHC 246, desculpe" (Alex dos Santos; março de 2004; Hortolândia, SP).

\section{Considerações finais}

Comecemos esta seção conclusiva pelo que o estudo não alcança: este trabalho não tem a pretensão de definir o perfil da criança que escreve a produtos jornalísticos realizados para esse público, como e por que o fazem. Analisamos aqui apenas um exemplo e é a ele que nos referimos ao discutir os resultados obtidos no estudo. É um caso, no entanto, bastante relevante no contexto jornalístico nacional, pois a $\mathrm{CHC}$ chega a uma quantidade razoável de escolas e, assim, tem um leitorado "possível" bastante alargado. É nesse espectro, ao mesmo tempo limitado e relevante, que as considerações que fazemos aqui devem ser entendidas.

Em termos etários, há certo destaque para os onze anos, como um pico de idade para a comunicação com a revista. Não se pode dizer que o dado obtido possa ser interpretado também como indício de que essa idade é mais comunicativa do que as restantes, porque a influência do estímulo escolar é grande na amostra da $\mathrm{CHC}$ (e ele pode estar concentrado nos anos escolares que correspondem a essa idade). Trata-se de um ponto que merece mais investigações, para entender se o 
período dos onze anos pode ser considerado uma idade vital para a participação do leitorado no jornalismo infantil no Brasil e entender as razões pelas quais isso acontece. De todo modo, pode-se pensar por outro viés: o de que as outras faixas etárias devam receber mais estímulos, seja por parte da escola, seja por parte das revistas, para interagir mais com os veículos jornalísticos produzidos para elas. Além disso, a comunicação entre as crianças e a revista se dá tanto por mensagens eletrônicas quanto por correio tradicional, ainda que nas cartas em papel o destaque se dê para as missivas assinadas coletivamente. Como dito, já que essas correspondências são frutos de ações principalmente de escolas públicas, isso pode ser lido como um possível indício das deficiências estruturais dessas escolas brasileiras e também das dificuldades dos professores em lidar com as novas tecnologias, como identificado em pesquisas anteriores.

Podemos então refletir sobre a pergunta de investigação deste trabalho: "As crianças vêm utilizando as novas formas digitais de participação para se comunicar com os jornalistas que escrevem produtos direcionados para elas, buscando influenciar o discurso jornalístico e exercer seu direito à representação?" O que se pode dizer é que os leitores escrevem com bastante intensidade à revista e que eles são majoritariamente crianças (e não adultos por elas responsáveis), que usam o correio eletrônico para essa atividade, ainda que não tenham abandonado o papel quando a comunicação é gerada em ambiente escolar. Isso mostra que a inserção digital tende a aumentar a comunicação on-line com os veículos de comunicação de papel, ainda que as crianças continuem demonstrando apreço pela publicação, no suporte físico. Além disso, esses meninos e meninas, de modo voluntário ou estimulado por professores, enxergam o espaço de correspondência de cartas como uma plataforma pela qual podem intervir na oferta editorial da publicação, mas de modo reforçador, ou seja, pedindo mais do que já veem e apreciam. Em resumo, as crianças veem os canais abertos pelas publicações como forma de poder interferir na produção jornalística, dizendo às redações para que não se desviem do rumo que tomaram e, ao contrário, reforcem a cobertura em determinadas áreas. 
Não se destacam na amostra pedidos para que os jornalistas traduzam o noticiário adulto para as crianças, já que isso não é preponderante na linha editorial do magazine. Mas as crianças dizem nas correspondências que gostam de se sentir bem informadas ou de descobrirem fatos novos. Elas, no entanto, não associam essas informações importantes para elas às notícias que usualmente estão presentes nos produtos do jornalismo adulto. Em vez disso, elas se interessam pela vida dos animais e pelo meio ambiente, por curiosidades, carreira, literatura, esportes e novidades sobre os seus ídolos. São assuntos, já identificados em pesquisas anteriores como de predileção das crianças e tradicionalmente abordados no jornalismo infantojuvenil ${ }^{16}$. Parecem ser temáticas que devem continuar presentes no cardápio informativo dos veículos para as crianças: elas se preocupam com a natureza, querem conhecer mais sobre os animais, anseiam por mais informações sobre as profissões que terão de escolher no futuro, sobre os seus ídolos e esportes preferidos, e querem se divertir com textos literários (ou até verem divulgados os que são de sua autoria). No entanto, não apareceram críticas a textos que tratam de acontecimentos jornalísticos relevantes no noticiário em geral, o que eventualmente é feito. Isso pode indicar que, se essa abordagem não é requisitada pelas crianças, ela também não é rejeitada. Ademais, as crianças fazem relativamente poucas críticas negativas ou indicam erros. Esse ponto, somado à falta de pedidos por mais notícias similares ao jornalismo para adultos, pode ser alvo de ações de mediações escolares ou parentais, para estimular o olhar mais analítico, para incentivar as crianças a pensaram sobre o que o jornalismo para elas destinado poderia ser, mas que ainda não é - sem que seja necessário abandonar o que vem sendo feito, mas acrescentando a ele inovações. e do Rio de Janeiro, as duas maiores cidades brasileiras. Esse resultado demostra à publicação a importância de elaborar reportagens que não se circunscrevam às cidades mais importantes do país, principalmente em assuntos que envolvem programações culturais. 


\section{Referências}

BARBOSA, A. F. (Coord.). TIC educação 2013: pesquisa sobre o uso das tecnologias de informação e comunicação nas escolas brasileiras. São Paulo: Comitê Gestor da Internet no Brasil, 2014a. Disponível em: <https://goo.gl/67HJy8>. Acesso em: 11 jul. 2017.

. (Coord.). TIC kids online Brasil 2013: pesquisa sobre o uso da internet por crianças e adolescentes no Brasil. São Paulo: Comitê Gestor da Internet no Brasil, 2014b. Disponível em: <https://goo.gl/73Np4t>. Acesso em: 11 jul. 2017.

BUCKINGHAM, D. O direito das crianças para os media. In: PONTE, C. (Org.). Crianças e jovens em notícia. Lisboa: Livros Horizonte, 2009. p. 15-27.

FOUCAULT, M. A ordem do discurso: aula inaugural no College de France pronunciada em 2 de dezembro de 1970. São Paulo: Loyola, 1998.

GALLAGHER, M. Foucault, power and participation. International Journal of Children's Rights, v. 16, n. 3, p. 395-406, 2008.

submetido em: 11 jul. 2017 | aprovado em: 16 ago. 2017 